\title{
Agent-User Concordance and Satisfaction with a Virtual Hospital Discharge Nurse
}

\author{
Shuo Zhou ${ }^{1}$, Timothy Bickmore ${ }^{1}$, Michael Paasche-Orlow ${ }^{2}$, Brian Jack ${ }^{2}$ \\ ${ }^{1}$ College of Computer and Information Science, Northeastern University, Boston, MA, USA \\ \{zhous06, bickmore\}@ccs.neu.edu \\ ${ }^{2}$ Boston University School of Medicine, Boston Medical Center, Boston, MA, USA \\ mpo@bu.edu,brian.jack@bmc.org
}

\begin{abstract}
User attitudes towards a hospital virtual nurse agent are described, as evaluated in a randomized clinical trial involving 764 hospital patients. Patients talked to the agent for an average of 29 minutes while in their hospital beds, receiving their customized hospital discharge instructions from the agent and a printed booklet. Patients reported very high levels of satisfaction with and trust in the nurse agent, preferred receiving their discharge instructions from the agent over their human doctors and nurses, and found the system very easy to use. Perceived similarity to the agent was a significant determiner of liking, trust, desire to continue, and working alliance, although perceived similarity was unrelated to racial concordance between patients and the agent.
\end{abstract}

Keywords: Relational agent, embodied conversational agent, medical informatics, health informatics, hospital discharge.

\section{Introduction}

Several studies have shown the positive effects of racial concordance between virtual agents and users on user satisfaction in laboratory or educational settings. However, none of these studies have determined whether these effects hold in real-world professional settings in which topics of significant gravity are discussed, such as medical consultations in a hospital. Although positive effects of concordance in human patient-provider interactions have also been demonstrated [1-4], it is unknown whether these effects would hold for virtual agents that are designed to counsel users about their health. It is possible that-given the importance of medical topics being discussed, or the distractions and stress in a real-world environment such as a hospitalsubtle factors such as the apparent race, gender, and age of a virtual agent are irrelevant.

As part of a large clinical trial to evaluate a virtual agent that plays the role of a hospital discharge nurse, we investigated whether racial concordance effects would still hold in a hospital setting. Few virtual agents have been evaluated in real-world professional settings such as hospitals. User reactions to virtual agents in laboratory settings always raise the issue of ecological validity; whether the experimental results would continue to hold in an uncontrolled work environment with study participants who are not college students. 


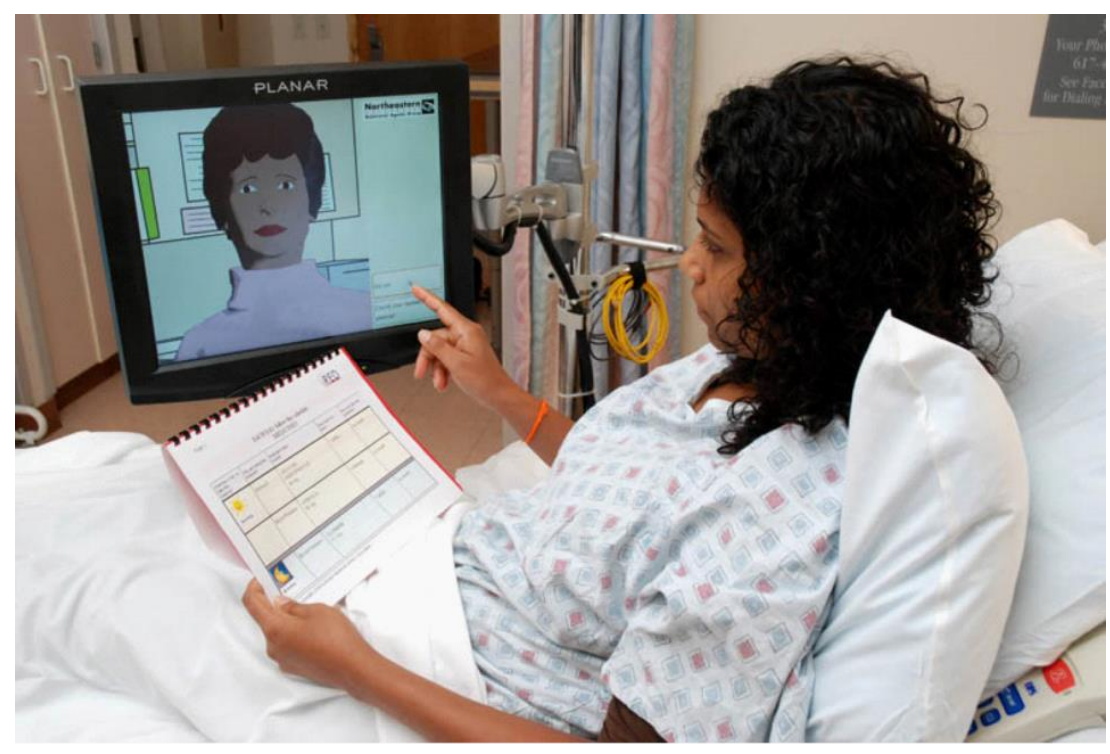

Figure 1. Virtual Hospital Discharge Nurse System

The hospital discharge process can be very complex and is the source of many medical errors. The average patient in our trial is discharged with ten medications and multiple follow up appointments. Approximately $20 \%$ of patients discharged from hospitals in the U.S. suffer adverse events and are re-hospitalized within 90 days, and approximately one third of these complications are preventable [5]. Among the leading reasons cited for these preventable complications are inadequate patient health literacy [6], patient lack of understanding of how to take their medications or of medication side effects, and low patient adherence to treatment regimens. The poor preparation of patients for hospital discharge is highlighted by studies showing that less than half of discharged patients know their diagnosis or the purpose of their medications [7].

We present the results of a clinical trial in which 764 hospital patients were randomized to be discharged by a virtual nurse agent $(\mathrm{N}=376$, Figure 1$)$ or standard procedure $(\mathrm{N}=388)$. Patients in the virtual nurse condition were further randomized to talk to a virtual agent that was designed to appear African American or Caucasian. In addition to assessing racial concordance objectively, we also asked patients to rate how similar they felt they were to the agent. We hypothesized that:

H1. Racial concordance would be a significant predictor of perceived similarity with the virtual agent.

H2. Perceived similarity would be a significant predictor of satisfaction with and trust in the virtual agent. 


\section{Related Work}

Patient-facing Hospital Information Systems. Within the hospital environment, most HCI research has been clinician-centric, although there is an emerging body of work on patient-facing systems. Bers, et al. provided immersive multi-user collaborative support environments for pediatric patients with renal and cardiac diseases [8], and other conditions. Wilcox, reports a series of design studies for patient-facing information systems in the hospital [9], and a subsequent pilot usability study of a prototype tablet-based system to provide hospital patients information about their care [10].

Within the medical community there are many in-hospital patient interfaces developed for medical interventions, such as VR-based analgesia [11]. Medical researchers have also developed several health education kiosks for placement in public spaces or clinic waiting rooms. One example is a waiting room touch screen kiosk for diabetes education, designed to accommodate patients with inadequate health literacy [12]. The system featured simplified navigation buttons and multimedia educational content and testimonials tailored to users' prior computer experience, learning styles and ethnicity. While this system was found to be fairly easy to use, its use did not lead to any significant differences in diabetes outcomes, compared to a control group, and the authors did not describe what design features they specifically included to address health literacy issues.

User-Agent Concordance. Baylor et al. conducted studies on the impact of racial and gender concordance between virtual agents and users in an educational application [13]. In one study, they developed several animated agents for an intelligent tutoring system that varied in race and gender. Study participants were 139 teachers enrolled in an introductory technology education class. Results indicated that teachers rated the agents of their own race more engaging and affable $(\mathrm{p}<.05)$. A follow-up study investigated what kind of virtual agent students would choose to work with. African American students selected African American characters more frequently, while white students preferred the white agents $(\mathrm{p}<.001)$. When asked why they made their choices, African American students often indicated that they wanted an agent that they could "better relate to" in terms of ethnicity and gender.

Persky et al. conducted a study on the effects of racial concordance between study subjects and simulated doctor agents that provided personalized cancer risk information. Subjects who interacted with a racially concordant virtual doctor were more accurate in their risk perceptions than those who interacted with a non-concordant virtual doctor, and this effect was amplified among current smokers [14].

\section{The Virtual Hospital Discharge Nurse}

The virtual discharge nurse system was developed over a course of three years by a multi-disciplinary design team comprised of HCI researchers, doctors and nurses, a health literacy expert, and programmers and animators [15]. The virtual nurse is deployed on a touch screen computer on a mobile kiosk that allows for patient education 
at the patient's hospital bedside (Figure 1). The kiosk consists of a wheeled base, a 4' tall stand and an articulated arm. The arm allows the screen to be positioned and tilted in front of a patient accommodating their mobility whether they are lying or sitting up in bed, or sitting in a chair.

The agent spends approximately half an hour with each patient before they leave the hospital, reviewing the layout and contents of the patient's discharge instruction booklet. The paper booklet is given to patients before their conversation with the agent, and the agent reviews a digital version of the booklet in the interface, so that patients can follow along with the agent's explanation in their paper booklets. The discharge conversation covers the patient's primary diagnosis, medications, follow-up appointments, and self-care procedures the patient will need to manage once they leave the hospital. The agent is also designed to talk with patients once a day, every day they are in the hospital, communicating all of the information that is known at that time about their diagnosis and post-discharge self-care regimen, in order to reinforce the information as much as possible. Dialogues were designed that describe 2,254 medicines - including brief descriptions, warnings, and side effects - in addition to the 48 most common diagnoses in the hospital.

The agent also tested patient understanding of key points using short "open book" tests during the interaction with a few multiple-choice questions. If a patient failed these tests, the agent helped them locate the information in their booklet. If the patient failed a subsequent comprehension test, or requested additional information about any part of the booklet, a report was printed with the patient's information needs for a human nurse to follow up with before the patient went home.
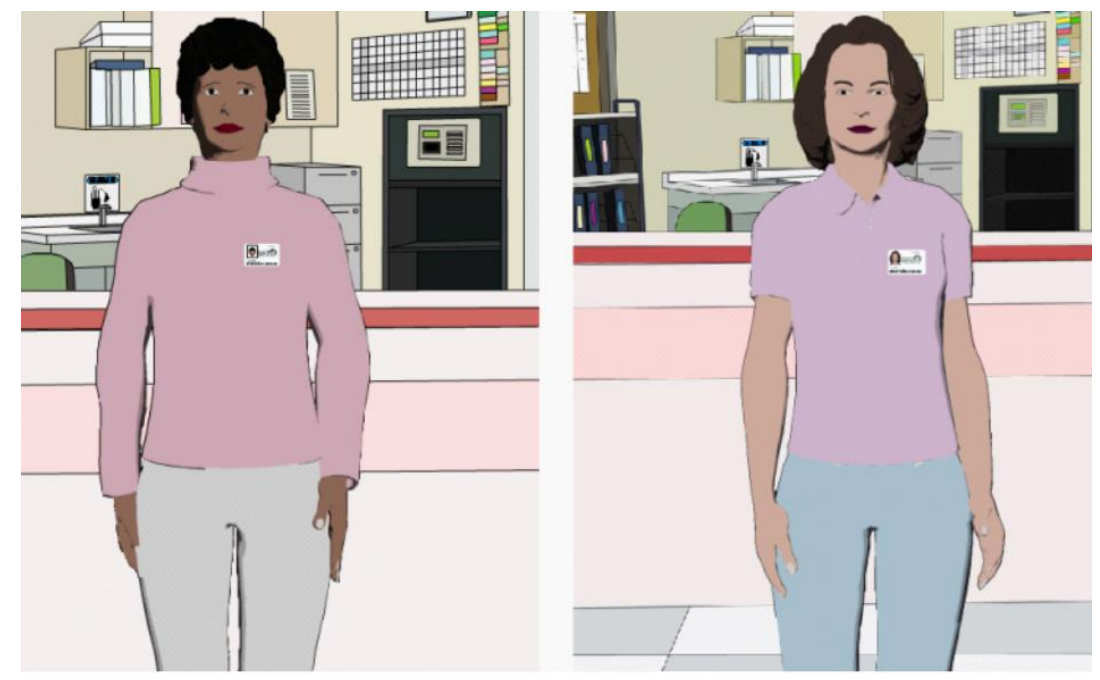

Figure 2. Virtual Nurse Characters, African American and Caucasian

The virtual agent is driven by a hierarchical transition-network based dialogue model that uses template-based text generation. The agent speaks using a synthetic voice, and displays animated nonverbal behavior (hand gestures, posture shifts, facial expressions, etc.) in synchrony with the speech, including deictic gestures towards a 
digital version of the patient's discharge instructions [16]. User contributions to the conversation are made by touching utterance option buttons on the touch screen display that are dynamically updated for each user speaking turn. Utterance option buttons are used to avoid any potential inaccuracy in this sensitive medical scenario.

Two female nurse characters were designed - one middle-aged Caucasian and one middle-aged African American - to better match the patient demographic at the Boston Medical Center where the clinical trial was conducted, and to improve acceptability of the agent (Figure 2). We originally designed eight character models of both genders and different ethnic groups, and conducted a survey of 32 hospital patients to select the two most acceptable characters. We also conducted surveys to select the synthetic voice that patients felt best matched each character from among a set of available commercial voices, and to determine given names for the characters.

\section{Randomized Clinical Trial}

We conducted a clinical trial to evaluate the Virtual Nurse system, with participants randomized between the Virtual Nurse and standard care in the hospital. The trial was conducted at Boston Medical Center, a 547 bed safety net hospital that serves an urban, $84 \%$ minority, traditionally underserved population. The patient population at Boston Medical center consists of 43\% African American, 29\% white, 19\% Hispanic or Latino, and other races. In addition to the primary trial randomization, intervention group patients were further randomized to either be discharged by the African American or Caucasian agent, and to either have a single interaction with the Virtual Nurse on the day of discharge, or one interaction every day they were in the hospital, including the day of discharge.

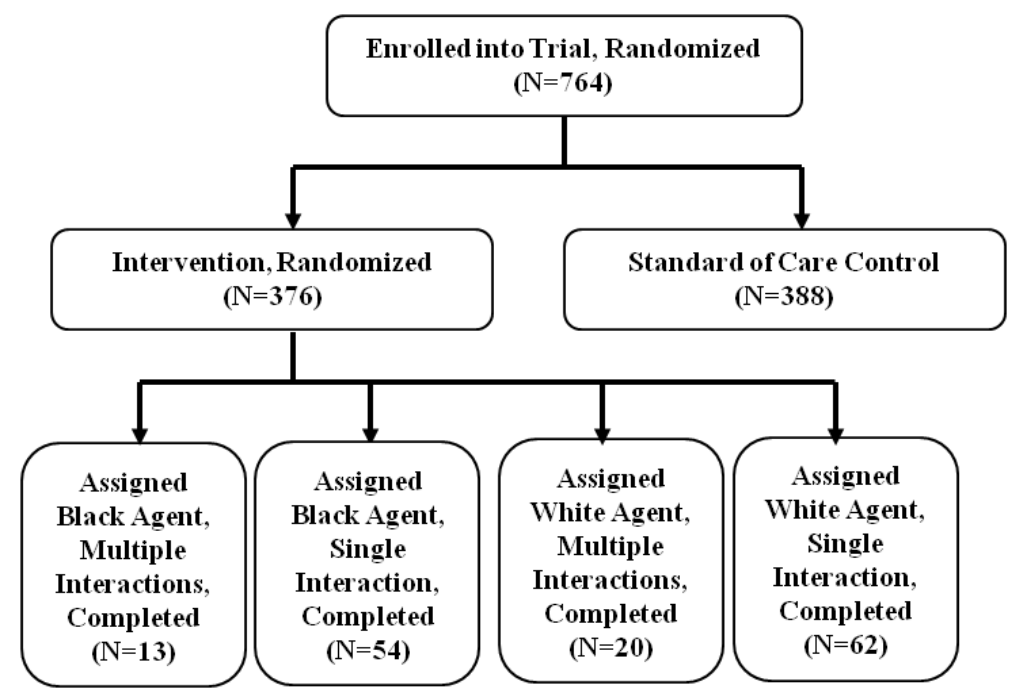

Figure 3. Subject Flow through Study 


\subsection{Clinical Trial Methods}

Participants. Figure 3 shows the flow of patients in this study and Table 1 shows the demographic breakdown. In total, 764 participants were recruited in this study and retained for analysis. All participants were patients admitted to a general medicine floor of Boston Medical Center, and 50.8\% were female, aged 18 to 90 years old (mean=49). Among all participants, 52.6\% were African American, 29.1\% were Caucasian, and $11.4 \%$ were Hispanic.

Table 1. Demographics of Intervention Subjects who Completed Surveys

(Education: <HS: less than high school, HS: high school, >HS: more than high school)

\begin{tabular}{|l|l|c|c|c|c|}
\hline \multicolumn{1}{|c|}{ Variable } & \multicolumn{1}{|c|}{$\begin{array}{c}\text { All } \\
\text { N=149 }\end{array}$} & $\begin{array}{c}\text { Black } \\
\text { Agent } \\
\text { N=67 }\end{array}$ & $\begin{array}{c}\text { White } \\
\text { Agent } \\
\text { N=82 }\end{array}$ & p \\
\hline Sex (Female) & $\mathrm{N}(\%)$ & $71(47.7)$ & $26(38.8)$ & $45(54.9)$ & 0.07 \\
\hline Age & Mean (SD) & $49.6(13.1)$ & $48.9(12.7)$ & $50.1(13.5)$ & 0.59 \\
\hline Race & Black, N(\%) & $81(54.4)$ & $34(50.8)$ & $47(57.3)$ & 0.15 \\
\hline Education & White, N(\%) & $40(26.8)$ & $23(34.3)$ & $17(20.7)$ & \\
\hline & Other, N(\%) & $28(18.8)$ & $10(14.9)$ & $18(22.0)$ & \\
\hline Married & $\mathrm{HS}, \mathrm{N}(\%)$ & $50(33.6)$ & $26(38.8)$ & $24(29.3)$ & \\
\hline $\begin{array}{l}\text { Health } \\
\text { Literacy } \\
\text { (Inadequate })\end{array}$ & $\mathrm{NHS}, \mathrm{N}(\%)$ & $52(34.9)$ & $23(34.3)$ & $29(35.4)$ & \\
\hline
\end{tabular}

Measures. Health literacy (an individual's ability to read and follow written medical instructions) was assessed at intake using the REALM instrument [17], in addition to computer literacy (single self-report item with $1=$ "I've never used a computer." to 4="I'm an expert."), and demographics (age, gender, race). Immediately following their interaction with the agent, participants completed a self-report questionnaire assessing working alliance (trust and belief in working with the agent to achieve a therapeutic outcome [18], scores ranging from 1-7), as well as the single scale item questions in Table 2 . 
Table 2. Self-Report Items Completed after Agent Interaction (“Elizabeth” is the agent's name)

\begin{tabular}{|l|l|l|}
\hline \multicolumn{1}{|c|}{ Question } & \multicolumn{1}{|c|}{ Anchor 1 } & \multicolumn{1}{c|}{ Anchor 7 } \\
\hline How satisfied were you with Elizabeth? & Not at all & Very satisfied \\
\hline How easy was talking to Elizabeth? & Easy & Difficult \\
\hline $\begin{array}{l}\text { How much would you like to continue } \\
\text { working with Elizabeth? }\end{array}$ & Not at all & Very much \\
\hline How much do you like Elizabeth? & Not at all & Very much \\
\hline $\begin{array}{l}\text { How would you characterize your rela- } \\
\text { tionship with Elizabeth? }\end{array}$ & Complete stranger & Close friend \\
\hline How much do you trust Elizabeth? & Not at all & Very much \\
\hline $\begin{array}{l}\text { How much do you feel that Elizabeth } \\
\text { cares about you? }\end{array}$ & Not at all & Very much \\
\hline $\begin{array}{l}\text { Would you rather have talked to your } \\
\text { doctor or nurse than Elizabeth? }\end{array}$ & definitely prefer doc- \\
tor or nurse & $\begin{array}{l}\text { definitely prefer } \\
\text { Elizabeth }\end{array}$ \\
\hline $\begin{array}{l}\text { How likely is it that you will follow Eliz- } \\
\text { abeth's advice? }\end{array}$ & Not at all likely & Very likely \\
\hline $\begin{array}{l}\text { How similar do you feel that you are to } \\
\text { Elizabeth? }\end{array}$ & Very different & Very similar \\
\hline
\end{tabular}

\subsection{Results}

Among the intervention group, 302 participants actually interacted with the agent, and 149 completed all questionnaires. Among these 149 patients, 116 had only a single interaction at the time of discharge, while 33 had multiple interactions during their hospital stay (up to 5 sessions)(Figure 3). The large number of patients who did not complete all study tasks was due to the challenging logistics of the study. Patients could not use the final discharge system until they had been approved for hospital discharge (an event we had no control over), the time between this approval and when patients could actually leave was highly variable, and patients were anxious to get home. The combination of these factors led to a large number of patients who were enrolled in our study leaving the hospital before we could configure the agent, run the interaction, and collect all measures. 
Overall, patients reported very high satisfaction with the agent (median="very satisfied"), very high ease of use (median="very easy"), and high working alliance with the agent (median=6, IQR=1.9). Participants in general liked the agent (median="like agent very much"), and trusted the agent (median="trust agent very much")(Figure 4). For the question whether they preferred to talk to the agent or their doctor or nurse, 49 out of 135 participants who answered this question clearly indicated that they preferred the agent, while only 33 indicated they preferred a human (Figure 5). Participants' answers were recorded based on a 7-point scale (Table 2), with 4 being neutral. Any answer higher than 4 was recorded as preference towards the agent.

Bivariate correlations among measures are shown in Table 3. Since most measures are single scale items, non-parametric tests are used throughout [19].

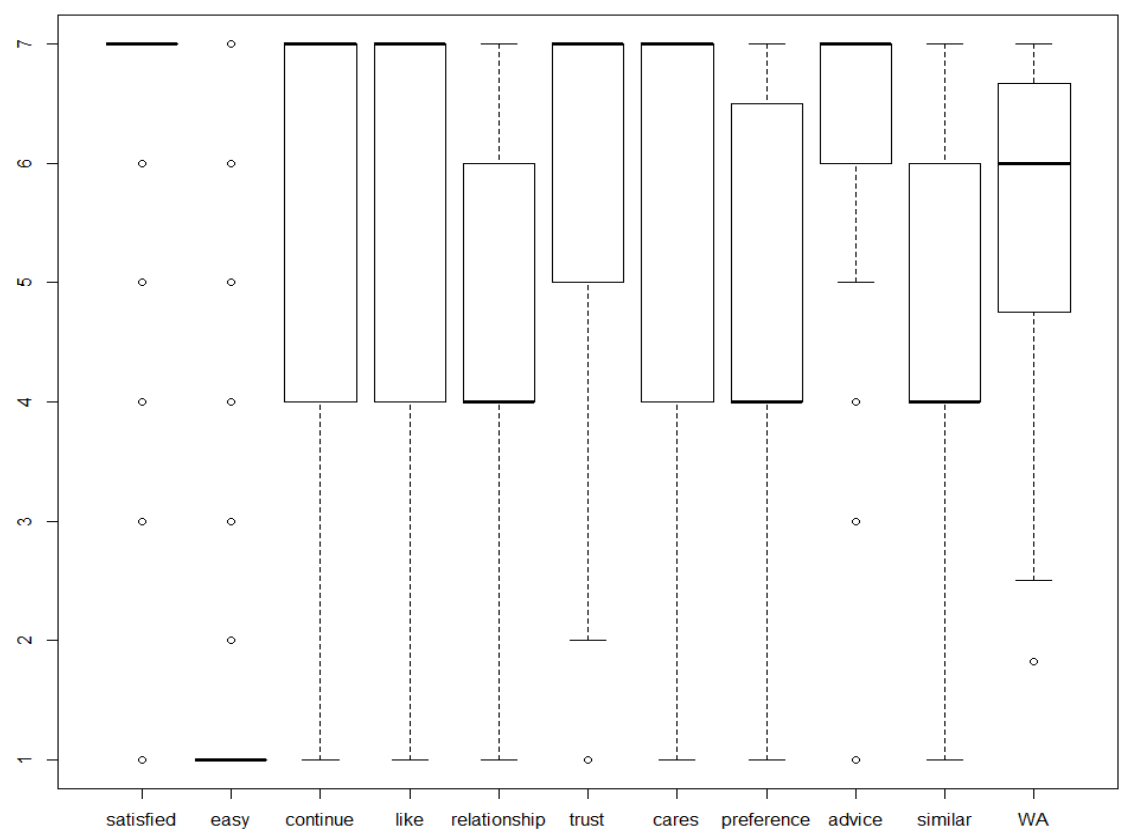

Figure 4. Boxplots (showing range, $1^{\text {st }}, 2^{\text {nd }}, 3^{\text {rd }}$ quartiles) of Self-Report Measures WA $=$ Working Alliance Bond Inventory Subscale Score

Racial Concordance. We created a racial concordance index by scoring ' 1 ' if both the agent and the user were African American, or both the agent and user were not African American, ' 0 ' otherwise. There was no significant relationship between this measure and perceived similarity, Mann-Whitney $U=1085$, n.s. There was a significant relationship between concordance and working alliance, Mann-Whitney U=2761, $\mathrm{p}=.03$, in which patients with racial concordance scored significantly lower compared to discordant patients. However, concordance was unrelated to any other measure (Table 3). 


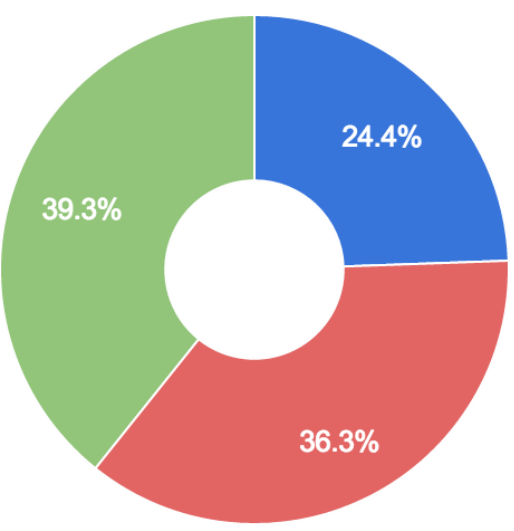

Prefer Doctor or Nurse

Prefer Agent

No Preference

Figure 5. Preference by Patients of Agent vs. Hospital Doctors or Nurses

Table 3. Bivariate Spearman Correlations among Measures (Non-parametric tests using Spearman's Rho)

Significant relationships $(\mathrm{p}<.05)$ in bold and marked with asterisk

\begin{tabular}{|c|c|c|c|c|c|c|c|c|c|c|c|}
\hline & \begin{tabular}{|l|} 
Per- \\
ceived \\
Simi- \\
larity
\end{tabular} & $\begin{array}{l}\text { Racial } \\
\text { Con- } \\
\text { cord- } \\
\text { ance } \\
\end{array}$ & $\begin{array}{l}\text { Health } \\
\text { Litera- } \\
\text { cy }\end{array}$ & $\begin{array}{l}\text { Satis- } \\
\text { fied }\end{array}$ & Trust & \begin{tabular}{|l} 
Ease of \\
Use
\end{tabular} & Liking & $\begin{array}{l}\text { Prefer- } \\
\text { ence }\end{array}$ & Caring & $\begin{array}{l}\text { Rela- } \\
\text { tion- } \\
\text { ship }\end{array}$ & $\begin{array}{l}\text { Work- } \\
\text { ing } \\
\text { Alli- } \\
\text { ance }\end{array}$ \\
\hline $\begin{array}{l}\text { Perceived } \\
\text { Similarity }\end{array}$ & 1.0 & 0.14 & -0.15 & $0.21 *$ & $0.41 *$ & -0.13 & $0.37 *$ & $0.37 *$ & $0.34 *$ & $0.32 *$ & $0.35 *$ \\
\hline \begin{tabular}{|l|} 
Racial \\
Concord- \\
ance \\
\end{tabular} & & 1.0 & -0.09 & 0.04 & -0.09 & 0.03 & -0.05 & -0.03 & -0.09 & -0.02 & $-0.19 *$ \\
\hline $\begin{array}{l}\text { Health } \\
\text { Literacy }\end{array}$ & & & 1.0 & $-0.18 *$ & -0.14 & 0.04 & -0.09 & -0.09 & -0.15 & $-0.19 *$ & -0.09 \\
\hline Satisfied & & & & 1.0 & $0.37 *$ & $-0.39 *$ & $0.42 *$ & 0.13 & $0.26^{*}$ & $0.23^{*}$ & 0.31* \\
\hline Trust & & & & & 1.0 & $-0.26^{*}$ & $0.44 *$ & 0.31* & $0.52 *$ & 0.33* & $0.57 *$ \\
\hline \begin{tabular}{|l|} 
Ease of \\
Use \\
\end{tabular} & & & & & & 1.0 & $-0.28 *$ & -0.03 & $-0.28 *$ & -0.09 & $-0.22 *$ \\
\hline Liking & & & & & & & 1.0 & 0.33* & 0.50* & $0.47 *$ & $0.54 *$ \\
\hline $\begin{array}{l}\text { Prefer- } \\
\text { ence }\end{array}$ & & & & & & & & 1.0 & $0.27 *$ & $0.36 *$ & 0.39* \\
\hline Caring & & & & & & & & & 1.0 & 0.48* & $0.61 *$ \\
\hline $\begin{array}{l}\text { Relation- } \\
\text { ship }\end{array}$ & & & & & & & & & & 1.0 & $0.35 *$ \\
\hline $\begin{array}{l}\text { Working } \\
\text { Alliance }\end{array}$ & & & & & & & & & & & 1.0 \\
\hline
\end{tabular}


Perceived Similarity. We investigated relationships between patient-rated perceived similarity with the agent and other outcome measures using Spearman's rho nonparametric correlation tests. Several significant relationships emerged. Patients who perceived higher similarity with the agent reported higher working alliance (rho $=.35$, $\mathrm{p}<.001)$, higher satisfaction ( $\mathrm{rho}=.21, \mathrm{p}<.05)$, greater desire to continue working with the agent $(\mathrm{rho}=.25, \mathrm{p}<.05)$, greater liking of the agent $(\mathrm{rho}=.37, \mathrm{p}<.001)$, greater trust in the agent $(\mathrm{rho}=.41, \mathrm{p}<.001)$, a closer relationship with the agent $(\mathrm{rho}=.32, \mathrm{p}=.001)$, and felt the agent cared more about them (rho=.34, $\mathrm{p}<.001$ ), compared to patients reporting lower similarity with the agent. Patients who reported higher similarity with the agent also said they were more likely to follow the agent's advice upon hospital discharge $(\mathrm{rho}=.19, \mathrm{p}=.07)$, and preferred receiving their discharge instructions from the agent (rho=.37, $\mathrm{p}<.001)$ compared to other patients.

Literacy. We also investigated relationships between computer literacy, health litera$\mathrm{cy}$, and attitudes towards the agent. We found a significant relationship between computer literacy and satisfaction with the agent, consistent with previous findings [20]. Patients with low computer literacy rated higher satisfaction compared to those with high computer literacy (Mann-Whitney $\mathrm{U}=3028.5, \mathrm{p}=.003$ ). Furthermore, patients with low computer literacy rated the agent higher on ease of use compared to other patients (Mann-Whitney $\mathrm{U}=2109.5, \mathrm{p}=.01$ ).

We also found effects of health literacy on participants' perceived relationship with the agent. Low health literacy patients reported closer relationships with the agent (Mann-Whitney U=3417, $\mathrm{p}=.02$ ) and greater perceptions of feeling cared for by the agent (Mann-Whitney U=3200.5, $\mathrm{p}<.08$ ) compared to high health literacy patients.

Using a non-parametric ANOVA [21], we also found significant main effect of health literacy on trust $(\mathrm{p}=.007)$ and a marginally significant interaction between health literacy and number of interactions with the agent (single vs. multiple) on trust $(\mathrm{p}=.08)$. In general, low health literacy participants trusted the agent more, and trust in the agent increased after more interactions with the agent, but only for patients with low health literacy (Figure 6).

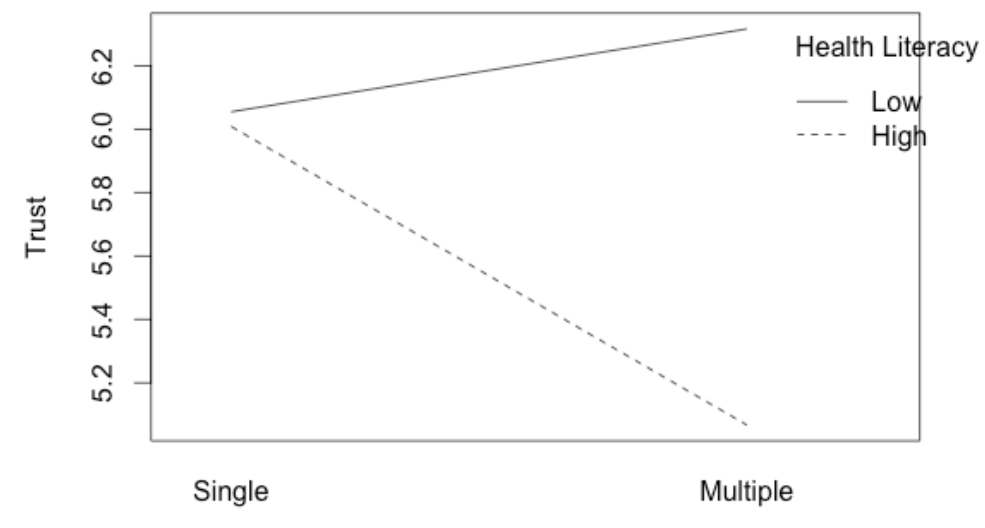

Number of Interactions

Figure 6. Effect of Health Literacy and Number of Interactions on Trust in Nurse Agent 
Number of Interactions. We also investigated relationships between the number of interactions a patient had with the nurse agent and their perceptions of the agent. We found that the more interactions a patient had, the closer their reported relationship (Mann-Whitney $\mathrm{U}=1571.5, \mathrm{p}=.06$ ).

\subsection{Factors Predicting Perceived Similarity with the Agent}

Given the number of significant correlations between perceived similarity and other measures, we sought to understand what patient factors predicted their assessment of similarity. We conducted a linear regression of patient demographic factors onto perceived similarity. The predictors included: racial concordance, gender, age, education level, and computer literacy. Results are shown in Table 4. Although none of the coefficients are significantly different from zero, gender, age, and racial concordance are trending. Female patients, older patients, and those who were racially concordant with the agent tended to rate their similarity higher.

Table 4. Regression Model of Patient Demographics on Perceived Similarity with Agent Multiple model $\mathrm{R}^{2}=0.095$

\begin{tabular}{|l|r|l|}
\hline \multicolumn{1}{|c|}{ Factor } & Coefficient & \multicolumn{1}{l|}{ P } \\
\hline (Intercept) & 3.073 & 0.006 \\
\hline Gender & -0.624 & 0.106 \\
\hline Age & 0.026 & 0.115 \\
\hline Education & -0.039 & 0.703 \\
\hline Racial Concordance & 0.698 & 0.070 \\
\hline Computer Experience & 0.032 & 0.898 \\
\hline
\end{tabular}

\subsection{Discussion}

In general, perceived similarity was found to significantly affect patients' working alliance, satisfaction, liking, trust, and relationship with the agent. We hypothesized that the racial-concordance between the patient and the agent would be a major predictor of perceived similarity, but this hypothesis was not supported by our results. Although trending was found in our preliminary linear model, racial concordance was not strongly correlated with perceived similarity. The trending for correlation between gender and perceived similarity can be explained since both agents used in the clinical trial were female characters. Trending for age could be explained as both characters were designed as middle-aged. Racial concordance slightly contributed to the per- 
ceived similarity according to the preliminary model, although a better model is needed to explain the relationship between racial concordance and perceived similarity.

Patients who reported higher similarity with the agent were more likely to prefer receiving their discharge instructions from the agent compared to other patients. Among all patients who answered the question about preference, 36.3\% ( $\mathrm{N}=49)$ said they would prefer the agent, $24.4 \%(\mathrm{~N}=33)$ preferred doctor or nurse, and $39.3 \%$ $(\mathrm{N}=53)$ indicated no preference. More than one-third of the participants who answered this question clearly indicated that they preferred the agent. Interviews with patients in the pilot study [15] provide some insight into why patients preferred the virtual nurse. Patients liked that the agent took as much time as was needed to go through all the details of the discharge booklet, and that the agent checked to make sure the patient understood what was being described:

- $\quad$ "I prefer Louise, she's better than a doctor, she explains more, and doctors are always in a hurry."

- $\quad$ "It was just like a nurse, actually better, because sometimes a nurse just gives you the paper and says 'Here you go.' Elizabeth explains everything."

- "Sometimes doctors just talk and assume you understand what they're saying. With a computer you can go slow, go over things again and she checks that you understand."

The clinical scenario of care transition and hospital discharge in which we placed the system may be particularly stressful for patients. The level of satisfaction participants had with our system may have been accentuated due to a high level of dissatisfaction participants feel with their health providers in this scenario. We did not measure dissatisfaction with human providers and did not explore in this study the extent to which perceived similarity with the agent might reflect perceived alienation from the human providers.

\section{Conclusions and Future Work}

We found many signification correlations between patients' perceived similarity to a virtual discharge nurse agent and their satisfaction with and preference for the agent. Thus, $\mathrm{H} 2$ was strongly supported. Surprisingly, perceived similarity was not strongly related to racial concordance, as predicted. Thus, H1 was not supported. Perceived similarity was related to a few other factors (such as a patient's age and gender) but the overall fit of the model was very poor, indicating there are yet unknown factors that lead patients to rate a virtual nurse agent as being similar to themselves. Possible factors include: the appearance of the agent (dress, hairstyle, apparent educational level and socioeconomic status), the qualities of the synthetic speech (accent, apparent personality, apparent ethnic or cultural background), similarity in health status and affective state, and differing interpretations of the role and status of the agent (same as a human vs. a computer program vs. a cartoon character). The exploration of these factors remains an open research problem.

Patients also reported a high level of trust in the agent, and this may have superseded any effects of racial concordance. Elements of the system, such as social talk, empathy, and engaging users to check comprehension, may have instilled trust despite 
the complexity of the material. This, together with the importance and volume of the information conveyed, may overwhelm the relatively subtle effects of agent appearance.

The results presented indicate that perceived similarity to a virtual agent is important in many serious task settings, and serve as a partial guide for the design of future virtual agents and their applications.

In our ongoing work we are developing a version of the virtual nurse that is persistent throughout a patient's hospital stay, and is equipped with a range of sensors so that it is aware of events in the hospital room. This "Hospital Buddy" is being designed to help patients communicate with their providers, manage their sleep, and track their symptoms while in the hospital [22].

Acknowledgments. Thanks to the many members of the Re-Engineered Discharge project team at Boston Medical Center and the Relational Agents Group at Northeastern University for their contributions to this work. This work was supported by grants from the NIH National Heart Lung and Blood Institute and the Agency for Healthcare Research and Quality.

\section{References}

1. King, W., Wong, M., Shapiro, M., Landon, B., Cunningham, W.: Does racial concordance between HIV-positive patients and their physicians affect the time to receipt of protease inhibitors? Journal of General Internal Medicine 19, 11461153 (2004)

2. Gordon, H., Street, R., Sharf, B., Souchek, J.: Racial differences in doctors' information-giving and patients' participation. Cancer 107, 1313-1320 (2006)

3. LaVeist, T., Nuru-Jeter, A., Jones, K.: The association of doctor-patient race concordance with health services utilization. J Public Health Policy 24, 312-323 (2003)

4. Saha, S., Komaromy, M., Koepsell, T., Bindman, A.: Patient-physician racial concordance and the perceived quality and use of health care. Archives of Internal Medicine 159, 997-1004 (1999)

5. Forster, A., Murff, H., Peterson, J., Gandhi, T., Bates, D.: The Incidence and Severity of Adverse Events Affecting Patients after Discharge from the Hospital. Annals of Internal Medicine 138, (2003)

6. Baker, D., Parker, R., Williams, M., Clark, S.: Health literacy and the risk of hospital admission. J Gen Intern Med 13, 791-798 (1998)

7. Makaryus, A., Friedman, E.: Patients' understanding of their discharge treatment plans and diagnosis at discharge. Mayo Clin Proc 80, 991-994 (2005)

8. Bers, M., Ackermanntt, E., Cassell, J., Donegan, B., Gonzalez-Heydrichttt, J., DeMaso, D., Strobeckerfi, C., Lualditi, S., Bromleytt, D., Karlint, J.: Interactive Storytelling Environments: Coping with Cardiac Illness at Boston's Children's Hospital. In: Conference Interactive Storytelling Environments: Coping with Cardiac Illness at Boston's Children's Hospital. (1998) 
9. Wilcox, L., Gatewood, J., Morris, D., Tan, D., Feiner, S., Horvitz, E.: Physician Attitudes about Patient-Facing Information Displays at an Urban Emergency Department. Proceedings of AMIA Washington, DC (2010)

10. Vawdrey, D., Wilcox, L., Collins, S., Bakken, S., Feiner, S., Boyer, A., Restaino, S.: A Tablet Computer Application for Patients to Participate in Their Hospital Care. American Medical Informatics Association (AMIA) Annual Meeting, pp. 1428-1435, Washington, DC (2011)

11. Hoffman, H., Seibel, E., Richards, T., Furness, T., Patterson, D., Sharar, S.: Virtual reality helmet display quality influences the magnitude of virtual reality analgesia. J Pain 7, 843-850 (2006)

12. Gerber, B.S., Brodsky, I.G., Lawless, K.A., et al.: Implementation and Evaluation of a Low-Literacy Diabetes Education Computer Multimedia Application. DIABETES CARE 28, 1574-1580 (2005)

13. Baylor, A., Shen, E., Huang, X.: Which Pedagogical Agent Do Learners Choose? The Effects of Gender and Ethnicity. E-Learn (World Conference on E-Learning in Corporate, Government, Healthcare, \& Higher Education), Phoenix, AZ (2003)

14. Persky, S., Kaphingst, K., Allen, V., Senay, I.: Effects of patient-provider race concordance and smoking status on lung cancer risk perception accuracy among African-Americans. Annals of Behaviroal Medicine 45, 308-317 (2013)

15. Bickmore, T., Pfeifer, L., Jack, B.W.: Taking the Time to Care: Empowering Low Health Literacy Hospital Patients with Virtual Nurse Agents In: Conference Taking the Time to Care: Empowering Low Health Literacy Hospital Patients with Virtual Nurse Agents (2009)

16. Bickmore, T., Pfeifer, L., Yin, L.: The Role of Gesture in Document Explanation by Embodied Conversational Agents. International Journal of Semantic Computing 2, 47-70 (2008)

17. Davis, T., Long, S., Jackson, R., et al.: Rapid estimate of adult literacy in medicine: a shortened screening instrument. Fam Med 25, 391-395 (1993)

18. Horvath, A., Greenberg, L.: Development and Validation of the Working Alliance Inventory. Journal of Counseling Psychology 36, 223-233 (1989)

19. Carifio, J., Perla, R.: Resolving the 50-year debate around using and misusing Likert scales. Medical Education 42, 1150-1152 (2008)

20. Bickmore, T., Pfeifer, L., Byron, D., Forsythe, S., Henault, L., Jack, B., Silliman, R., Paasche-Orlow, M.: Usability of Conversational Agents by Patients with Inadequate Health Literacy: Evidence from Two Clinical Trials. Journal of Health Communication 15, 197-210 (2010)

21. Wobbrock, J., Findlater, L., Gergle, D., Higgins, J.: The Aligned Rank Transform for Nonparametric Factorial Analyses Using Only ANOVA Procedures. Human Factors in Computing Systems (CHI), (2011)

22. Bickmore, T., Bukhari, L., Vardoulakis, L., Paasche-Orlow, M., Shanahan, C.: Hospital Buddy: A Persistent Emotional Support Companion Agent for Hospital Patients. Intelligent Virtual Agents, Santa Cruz, CA (2012) 